\title{
Dissecting complex epigenetic alterations in human lupus
}

\author{
Dipak R Patel' and Bruce C Richardson ${ }^{* 1,2}$
}

\begin{abstract}
Systemic lupus erythematosus is a chronic relapsing autoimmune disease that primarily afflicts women, and both a genetic predisposition and appropriate environmental exposures are required for lupus to develop and flare. The genetic requirement is evidenced by an increased concordance in identical twins and by the validation of at least 35 single-nucleotide polymorphisms predisposing patients to lupus. Genes alone, though, are not enough. The concordance of lupus in identical twins is often incomplete, and when concordant, the age of onset is usually different. Lupus is also not present at birth, but once the disease develops, it typically follows a chronic relapsing course. Thus, genes alone are insufficient to cause human lupus, and additional factors encountered in the environment and over time are required to initiate the disease and subsequent flares. The nature of the environmental contribution, though, and the mechanisms by which environmental agents modify the immune response to cause lupus onset and flares in genetically predisposed people have been controversial. Reports that the lupus-inducing drugs procainamide and hydralazine are epigenetic modifiers, that epigenetically modified T cells are sufficient to cause lupus-like autoimmunity in animal models, and that patients with active lupus have epigenetic changes similar to those caused by procainamide and hydralazine have prompted a growing interest in how epigenetic alterations contribute to this disease. Understanding how epigenetic mechanisms modify T cells to contribute to lupus requires an understanding of how epigenetic mechanisms regulate gene expression. The roles of DNA methylation, histone modifications, and microRNAs in lupus pathogenesis will be reviewed here.
\end{abstract}

*Correspondence: brichard@med.umich.edu

'Division of Rheumatology, Department of Internal Medicine, University of Michigan, 300 North Ingalls Building, Room 7C27, Ann Arbor, MI 48109-5422, USA Full list of author information is available at the end of the article

\section{Epigenetics and gene expression}

Epigenetics is defined as heritable changes in gene expression that do not involve a change in the DNA sequence, and the mechanisms include DNA methylation, a variety of covalent histone modifications, and microRNAs (miRNAs). DNA is packaged in the nucleus as chromatin. Chromatin consists of DNA wrapped twice around a histone core to form a nucleosome, and the nucleosomes are stacked into higher-ordered structures to form the chromatin fiber that makes each chromosome. The DNA in chromatin is tightly packaged and inaccessible to the protein complexes that initiate RNA transcription. DNA methylation and histone modifications regulate gene expression by modifying chromatin structure to permit or prevent access of the transcription complexes to the DNA (Figure 1). In contrast, miRNAs target mRNAs for degradation. All three mechanisms DNA methylation, histone modifications, and miRNAs are being explored in human lupus.

\section{DNA methylation}

DNA methylation refers to the methylation of cytosines in CpG pairs and silences genes by stabilizing chromatin in the tightly packaged, transcriptionally repressive configuration. DNA methylation patterns are established during development and serve in part to silence genes which would be inappropriate or detrimental to the function of any given cell but for which a cell might have transcription factors that would otherwise drive their expression. Different cell types have different functions, determined by the repertoire of genes they express, so each cell type has a distinct pattern of methylated and unmethylated genes.

Once established, the methylation patterns are replicated each time a cell divides by DNA methyltransferase 1 (Dnmt1). As cells enter S phase, Dnmt1 levels increase. Dnmt1 binds the DNA replication fork and reads CpG pairs. Where deoxycytosine $(\mathrm{dC})$ in the parent strand is methylated, Dnmt1 transfers the methyl group from Sadenosylmethionine (SAM) to the corresponding $\mathrm{dC}$ in the daughter strand to form deoxymethylcytosine, replicating the methylation patterns and producing S-adenosylhomocysteine (SAH), an inhibitor of transmethylation 


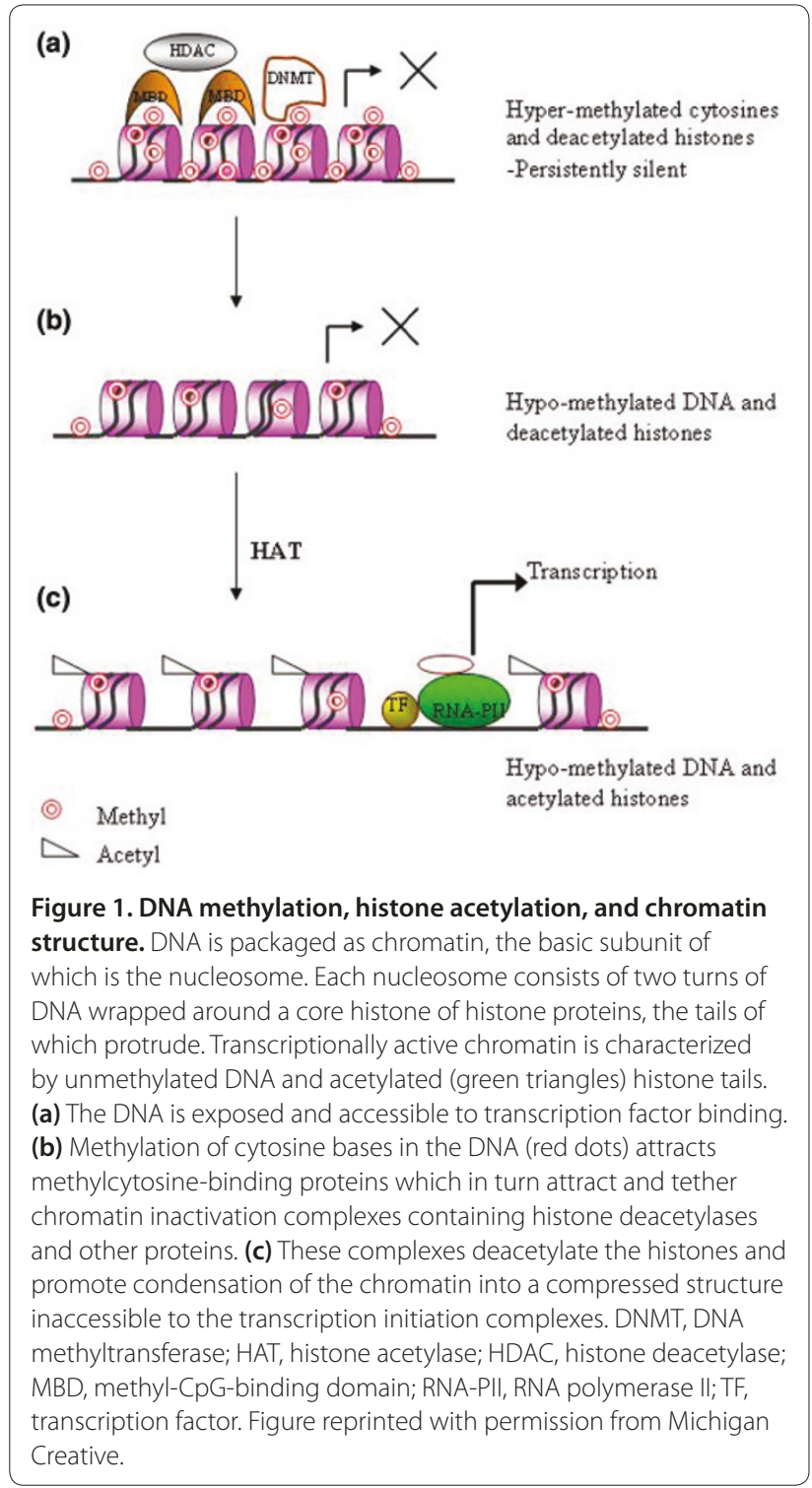

reactions [1]. Importantly, this reaction is sensitive to environmental agents and drugs that decrease Dnmt1 activity, decrease SAM, or increase SAH, preventing methylation of newly synthesized DNA in the daughter cells and causing inappropriate gene expression [1-3]. Furthermore, the errors can be replicated during subsequent rounds of cell division and accumulate over time, causing an age-dependent decrease in DNA methylation and increase in aberrant T-cell gene expression [4]. These age-dependent changes are evidenced by a report that lymphocyte DNA methylation patterns are the same in identical twins at 3 years of age but different at 50. DNA methylation patterns also diverged more when twins had different lifestyles or spent less of their lives together, compared to twins who had similar lifestyles or spent more of their lives together [5].

\section{T-cell DNA methylation and gene expression}

$\mathrm{T}$ lymphocytes are particularly dependent on DNA methylation to suppress inappropriate gene expression. $\mathrm{T}$ cells differentiate into multiple subsets throughout life but have overlapping sets of transcription factors and use DNA methylation to silence genes inappropriate for specific subsets. Like other cells, resting T cells express relatively little Dnmt1, but as $\mathrm{T}$ cells enter mitosis, signals through the extracellular-signal-regulated kinase (ERK) and c-Jun N-terminal kinase (JNK) pathways upregulate Dnmt1 to replicate the methylation patterns; and decreasing Dnmt1 enzymatic activity with inhibitors like 5-azacytidine (5-azaC) or procainamide, or preventing Dnmt1 upregulation with signaling inhibitors like hydralazine, prevents the methylation of the newly synthesized DNA, activating normally silenced genes and altering effector functions in the daughter cells [1]. For example, inhibiting DNA methylation induces interferon-gamma (IFNY) in Th2 cells, FoxP3 in CD4 ${ }^{+} \mathrm{CD} 25^{-} \mathrm{T}$ cells [6], and others [7].

Inhibiting DNA methylation also makes $\mathrm{CD} 4^{+} \mathrm{T}$ cells autoreactive to self class II major histocompatibility complex (MHC) molecules. The autoreactivity is due to LFA-1 (lymphocyte function-associated antigen 1) (CD11a/ CD18) overexpression, and increasing LFA-1 by transfection makes $\mathrm{T}$ cells similarly autoreactive [1]. Importantly, $\mathrm{CD} 4^{+} \mathrm{T}$ cells similarly responding to class II MHC molecules cause a lupus-like disease in the chronic graftversus-host disease model [8], suggesting that demethylated, autoreactive $\mathrm{T}$ cells may cause a similar lupus-like disease. This was confirmed by treating mouse $\mathrm{CD} 4^{+}$ $\mathrm{T}$ cells with 5-azaC and then injecting the cells into genetically identical mice. The recipients developed antidsDNA antibodies and an immune complex glomerulonephritis closely resembling human lupus nephritis [9].

The observation that 5-azaC, a drug that inhibits DNA methylation, can cause a lupus-like disease suggested that drugs which cause a lupus-like disease may be DNA methylation inhibitors. Subsequent studies demonstrated that $\mathrm{CD} 4^{+} \mathrm{T}$ cells treated with procainamide or hydralazine, which cause antinuclear antibodies (ANAs) in a majority of people and a lupus-like disease in genetically predisposed people, are also DNA methylation inhibitors [10] and that, when injected into genetically identical mice, mouse $\mathrm{T}$ cells treated with these drugs also caused a lupus-like disease [9]. Procainamide was found to inhibit Dnmt1 enzymatic activity, whereas hydralazine decreases Dnmt1 levels in dividing cells by inhibiting ERK pathway signaling [1].

Functional studies demonstrated that experimentally demethylated, autoreactive $\mathrm{CD} 4^{+} \mathrm{T}$ cells are cytotoxic and kill autologous or syngeneic macrophages $(M \phi)$, causing release of apoptotic nuclear material as well as impairing its clearance, since $M \phi$ clear apoptotic debris [1]. Others have reported that injecting apoptotic cells 
into mice or impairing their clearance through genetic manipulation is sufficient to cause anti-DNA antibodies and a lupus-like disease [11], suggesting that the $M \phi$ apoptosis caused by demethylated $\mathrm{T}$ cells contributes to anti-DNA antibody development. The demethylated $\mathrm{CD}^{+} \mathrm{T}$ cells also overstimulate B-cell antibody production through demethylation and overexpression of B-cell co-stimulatory genes, including CD70, CD4OL, IFN $\gamma$, and others $[1,12,13]$. When injected into mice, the demethylated cells accumulate in the spleen, where they kill $\mathrm{M} \phi$ and stimulate B cells, and removing the spleen prior to injection prevents disease development [14].

\section{T-cell DNA demethylates in patients with active lupus}

These studies demonstrate that epigenetically altered $\mathrm{CD}^{+} \mathrm{T}$ cells are sufficient to cause a lupus-like disease in mice. Since the two drugs that most commonly cause drug-induced lupus are DNA methylation inhibitors, these studies also suggest that epigenetically altered $\mathrm{CD}^{+} \mathrm{T}$ cells may similarly cause idiopathic lupus. This was initially tested by comparing overall DNA methylation levels in $\mathrm{T}$ cells from patients with active lupus, inactive lupus, or other rheumatic and inflammatory diseases and healthy controls. Patients with active lupus had lower methylcytosine levels than the other groups [15]. Interestingly, T-cell DNA methylation levels also decline with age [16], suggesting an explanation for the development of ANAs with age in otherwise healthy older people [17].

The decrease in lupus T-cell Dnmt1 levels was traced to decreased ERK pathway signaling, which prevents Dnmt1 upregulation during mitosis [1]. A role for decreased signaling in lupus pathogenesis was confirmed by experiments demonstrating that inhibiting ERK pathway signaling with MEK inhibitors also inhibited DNA methylation in mouse $\mathrm{CD}^{+} \mathrm{T}$ cells, and injecting the treated cells into syngeneic mice also caused a lupus-like disease [1]. More recently, a double-transgenic mouse strain was generated in which expression of a dominant negative MEK (dnMEK) could be selectively induced in $\mathrm{T}$ cells by adding doxycycline to their drinking water. Activating the dnMEK inhibited T-cell DNA methylation and caused anti-DNA antibodies and an 'interferon signature' in mice, similarly to what was observed in patients with lupus [18]. Interestingly, no kidney disease was seen in these transgenic mice on a BL6 background. However, crossing the double-transgenic BL6 strain with SJL mice, which have lupus genes, resulted in the development of an immune complex glomerulonephritis as well as anti-DNA antibodies when doxycycline was given [19]. Thus, impaired T-cell ERK pathway signaling is sufficient to cause lupus-like autoantibodies in nonlupus-prone mice, but renal disease also requires lupus genes.
Evidence that hydralazine inhibits ERK pathway signaling, that ERK pathway signaling is impaired in $\mathrm{T}$ cells from patients with active lupus, and that inhibiting ERK pathway signaling causes a lupus-like disease in adoptive transfer and transgenic mouse models [20] prompted studies identifying the signaling molecule(s) inactivated by hydralazine and inactivated in $\mathrm{CD} 4^{+} \mathrm{T}$ cells from patients with active lupus. The ERK pathway defect was traced to PKCS, which fails to respond to direct stimulation with phorbol myristate acetate in both the idiopathic lupus and hydralazine-induced models [3]. Importantly, PKCS 'knockout' mice develop lupus [20], demonstrating a critical role for PKC $\delta$ in lupus-like autoimmunity.

More recent studies demonstrate that PKC $\delta$ is inactivated by oxidative damage in lupus $\mathrm{T}$ cells. Lupus onset and flares are associated with environmental agents that cause oxidative stress, such as ultraviolet light exposure, acute infections, silica exposure, and smoking [21], and all cause oxidative stress [22]. Furthermore, lupus flares are characterized by biomarkers of oxidative stress such as protein nitration, caused by superoxide $\left(\mathrm{O}_{2}^{-}\right)$combining with nitric oxide (NO), an intracellular signaling molecule, to form peroxynitrite $\left(\mathrm{ONOO}^{-}\right)$[23]. T-cell PKC $\delta$ is nitrated in patients with active lupus, and the nitrated fraction is catalytically inactive [3], providing a direct link between environmental agents associated with lupus and epigenetic changes in T cells.

\section{Lupus T-cell epigenomics}

The observation that experimentally demethylated $\mathrm{CD} 4^{+}$ $\mathrm{T}$ cells overexpress LFA-1 due to ITGAL (CD11a) demethylation, making them autoreactive [1], raised the possibility that other genes may similarly demethylate and be inappropriately overexpressed by $\mathrm{T}$ cells from patients with active lupus. Additional genes were sought by treating normal human $\mathrm{CD} 4^{+} \mathrm{T}$ cells with 5 -azaC and comparing gene expression with mRNA expression arrays. These experiments identified CD70 (TNFSF7), perforin (PRF1), and the KIR gene family as genes primarily regulated by DNA methylation in $\mathrm{CD} 4^{+} \mathrm{T}$ cells. CD70 is expressed on some but not all CD4 $4^{+} \mathrm{T}$ cells and promotes B-cell antibody production [1]. Perforin is a cytotoxic molecule expressed in killer cells and lyses target cells by forming a pore in their cytoplasmic membrane [1]. The KIR genes normally are expressed by natural killer (NK) cells but not $\mathrm{T}$ cells and encode proteins that recognize I MHC molecules. Stimulatory Kir proteins mediate cytotoxic and inflammatory responses. Aberrant expression of KIR genes by demethylated $\mathrm{T}$ cells makes them likely candidates for contributing to autoimmune responses [24].

The DNA sequences demethylated to activate these genes were identified by bisulfite sequencing. Bisulfite converts cytosine to uracil but does not affect methylcytosine, 
and the change can be detected by DNA sequencing. Bisulfite sequencing revealed that regulatory sequences upstream of the CD11a, CD70, KIR, and perforin genes all demethylate in 5-azaC-treated $\mathrm{CD}^{+} \mathrm{T}$ cells, and methylation of these regions in transfection experiments silenced these genes [1,25].

Subsequent experiments compared expression and methylation of the same genes in $\mathrm{CD}_{4}^{+} \mathrm{T}$ cells from patients with either inactive or active lupus. As predicted, CD11a, perforin, and the KIR genes were overexpressed in patients with active but not inactive lupus, and the same sequences demethylated in proportion to disease activity and gene overexpression in these patients $[1,24]$. The exception was $C D 70$, which remains demethylated once it demethylates [1]. Others have reported that protein phosphatase $2 \mathrm{~A}$, a signaling molecule, is also demethylated and overexpressed in $\mathrm{T}$ cells from patients with active lupus [26]. Very recently, Jeffries and colleagues [27] used microarrays to survey hypomethylated and hypermethylated genes in $\mathrm{CD} 4^{+} \mathrm{T}$ cells from patients active lupus and identified 236 hypomethylated and 105 hypermethylated sites, confirming widespread methylation changes throughout the genome.

Together, these results demonstrate that inhibiting T-cell DNA methylation, either with drugs in vitro or environmental agents in patients with lupus, causes the same epigenetic changes in DNA methylation patterns and overexpression of the same genes. Since similar demethylated $\mathrm{T}$ cells cause lupus-like autoimmunity in mice, these studies indicate that T-cell DNA demethylation is likely fundamental to lupus onset and flares.

\section{Histone modifications}

Histone modifications also regulate gene expression. Histone acetyltransferases (HATs) and histone deacetylases (HDACs) regulate gene expression by adding or removing acetyl groups on lysine residues in the histone proteins [28]. Acetylation neutralizes the positive charge of lysines, weakening electrostatic DNA-histone interactions and increasing DNA accessibility for gene expression [29]. Conversely, deacetylation strengthens DNAhistone interactions, decreasing DNA accessibility and subsequent gene expression [30]. Promoters of actively transcribed genes are also characterized by methylation of lysine 4 on histone H3 (H3K4) and of lysine 36 on H3 (H3K36) [31]. In contrast, inactive genes are methylated at $\mathrm{H} 3 \mathrm{~K} 27$ and permanently silenced genes are frequently methylated at H3K9 [32]. A large number of other histone modifications serve a number of regulatory and other functions (reviewed in [33]).

\section{Lupus T-cell histone modifications}

Histone acetylation may also contribute to lupus pathogenesis. Hu and colleagues [34] showed that SLE CD4 ${ }^{+}$
$\mathrm{T}$ cells have decreased overall acetylation of histones $\mathrm{H} 3$ and $\mathrm{H} 4$, and the degree of $\mathrm{H} 3$ deacetylation correlated inversely with SLE disease activity. This raises the possibility that decreased histone acetylation contributes to lupus pathogenesis by promoting silencing of some genes. However, the genes affected are unclear.

Histone methylation patterns are also altered in $\mathrm{CD} 4^{+}$ lupus T cells [35]. Hu and colleagues [34] also reported hypomethylation at lysine 9 of histone H3 (H3K9) in SLE $\mathrm{CD}^{+}{ }^{+} \mathrm{T}$ cells, compared with healthy controls. mRNA levels of the histone methyltransferases SUV39H2 and EZH2 were also decreased in CD4+ SLE T cells [34]. Zhao and colleagues [36] subsequently reported that a different histone methyltransferase, SUV39H1, is recruited to the CD11a and CD70 promoters. This is mediated by RFX1, and RFX1 is downregulated in lupus CD4 ${ }^{+} \mathrm{T}$ cells [36]. RFX1 recruitment to SUV39H1 causes both increased H3K9 methylation and decreased CD11a and CD70 expression [35]. In a second report, Zhou and colleagues [37] showed increased H3K4 methylation at the CD70 promoter in lupus $\mathrm{CD}^{+} \mathrm{T}$ cells. Zhang and colleagues [38] showed that hematopoietic progenitor kinase 1 (HPK1) levels are decreased in lupus $\mathrm{CD}^{+}$ $\mathrm{T}$ cells. Furthermore, blocking HPK1 expression increased T-cell proliferation, cytokine secretion, and B-cell costimulatory functions. These changes reversed when HPK1 was overexpressed. The decreased HPK1 expression in lupus $\mathrm{CD}^{+} \mathrm{T}$ cells is due to decreased H3K27 methylation, and the decreased methylation is due to decreased binding of the enzyme jumonji domain containing 3 (JMJD3), which methylates H3K27 [38].

\section{MicroRNAs}

MiRNAs are 18- to 22-nucleotide non-coding RNA molecules that regulate gene expression by degrading mRNA or blocking protein translation. An miRNA binds to a target sequence in the 3 ' untranslated region of its target mRNA, leading to either degradation or translational silencing by other mechanisms. Multiple miRNAs can bind to and block expression of a target mRNA. Additionally, a single miRNA can bind to and block the expression of multiple target mRNAs. These events are possible because the sequences that mediate binding between an miRNA and mRNA are short and thus recognizable by many miRNAs [39].

Interestingly, histone modifications and DNA methylation also affect miRNAs in lupus $\mathrm{CD} 4^{+} \mathrm{T}$ cells. Ding and colleagues [40] showed that miR-142-3p and -5p are decreased in lupus $\mathrm{CD} 4^{+} \mathrm{T}$ cells. This causes overexpression of SLAM-associated protein, IL-10, and CD84. H3K27 methylation levels were increased in the putative miR-142 regulatory regions. The three $\mathrm{CpG}$ pairs closest to the miR-142 transcription start site were also hypermethylated in lupus $\mathrm{CD}^{+} \mathrm{T}$ cells, but average 
methylation of $11 \mathrm{CpG}$ pairs across the miR-142 regulatory region was not different in lupus $\mathrm{CD} 4^{+} \mathrm{T}$ cells [40].

\section{Lupus T-cell miRNAs}

$\mathrm{Yu}$ and colleagues [41] provided the first report of a possible role for miRNAs in autoimmune diseases. Sanroque mice, which have a defect in Roquin, develop a lupus-like syndrome attributed to increased ICOS (inducible co-stimulatory molecule) expression on T cells. A sequence in the ICOS 3' untranslated region is required for Roquin to block ICOS expression, and this sequence is recognized by miR-101 [41]. MiR-101 does not completely explain Roquin's ability to block ICOS expression, although other miRNAs could also be responsible.

Multiple miRNAs are differentially expressed in $\mathrm{CD}^{+}$ $\mathrm{T}$ cells from patients with lupus compared with healthy donors, and two recent reports link miRNAs and DNA methylation. MiRNAs-21, -126 , and -148a are upregulated in $\mathrm{CD} 4^{+}$lupus $\mathrm{T}$ cells and decrease Dnmt1 expression [42,43]. MiRNAs-126 and -148a decrease Dnmt1 directly. MiR-21 decreases RASGRP1, in the JNK signaling pathway, which leads to decreased Dnmt1 expression. Blocking miR-21, 126, or 148a in lupus $\mathrm{CD}^{+} \mathrm{T}$ cells increases Dnmt1 levels and decreases CD70 and CD11a levels. MiR-21 is also increased in $\mathrm{CD}^{+}$lupus $\mathrm{T}$ cells [44], and blocking miR-21 expression decreases levels of the methylation-sensitive gene CD40L. Blocking miR-21 also decreases proliferation, IL-10 expression, and B-cell maturation. Overexpressing miR-21 has opposing effects, including increased CD40L expression. A therapeutic potential for miRNAs is shown in these cases since blocking their expression reverses lupus-like phenotypes.

Effects of miRNAs in total $\mathrm{CD}^{+}{ }^{+} \mathrm{T}$ cells and PBMCs from patients with lupus have also been studied. For example, miR-31 and IL-2 levels are decreased in lupus $\mathrm{T}$ cells. This effect is mediated by RhoA, which blocks IL-2 expression. MiR-31 decreases RhoA, which increases IL-2 [45]. MiR-125a is also decreased, and RANTES (regulated and normal $\mathrm{T}$ cell expressed and secreted) increased, in lupus $\mathrm{T}$ cells, and these effects are mediated by interactions between miR-125a and KLF13, a regulator of RANTES expression [46]. Again, suppressing these miRNAs in lupus $\mathrm{T}$ cells reversed the defects in IL-2 and RANTES expression. MiR-146a is also downregulated in lupus PBMCs. MiR-146a negatively regulates IFN- $\alpha / \beta$ expression by targeting STAT-1 and IRF-5, suggesting a link between miR-146a and lupus pathogenesis [47].

Mouse models corroborate these findings. MiR-21 is increased in $\mathrm{CD}^{+} \mathrm{T}$ cells from lupus-prone B6.Sle123 mice, and blocking miR-21 expression decreases splenomegaly [48]. Suppressing miR-21 also increases PDCD4 expression. PDCD4 is decreased in $\mathrm{CD} 4{ }^{+} \mathrm{T}$ cells from patients with lupus, and miR-21 suppresses PDCD4 when transfected into normal CD4+ $\mathrm{T}$ cells [44].

\section{Genetic/epigenetic interactions in lupus}

As discussed above, lupus develops when genetically predisposed people encounter environmental agents that initiate disease onset and flares, and the environment appears to trigger lupus onset and flares at least in part by modifying T-cell DNA methylation. The relationship between T-cell DNA demethylation and genetic predisposition is complex because both can vary. T-cell DNA demethylates in lupus, and the degree of DNA demethylation is directly related to lupus flare severity [1]. Genetic predisposition to lupus approximates a continuous variable. So far, 38 lupus single-nucleotide polymorphisms (SNPs), each with its own relative risk or odds ratio for lupus, have been identified [49]. These genes assort largely independently, so any given person can inherit 0 to 38 distinct lupus genes, with 0,1 , or 2 copies of each. It is reasonable to propose that those with a higher total genetic risk for lupus may have more problems with lupus than those with a lower genetic risk.

\section{Genetic/epigenetic interactions and age of lupus onset}

The variable nature of T-cell DNA demethylation and genetic risk suggests that the degree of T-cell DNA demethylation may interact with total genetic predisposition to initiate lupus onset and flares in any given person. One example of this interaction is suggested by a study relating age of lupus onset to genetic risk. T-cell DNA demethylates with age [4], and T-cell DNA demethylation contributes to lupus flares [1]. The age of lupus onset is also variable [50]. Typing for 19 risk alleles, this study confirmed that those developing lupus early in life had a greater genetic risk than those developing lupus later, and some differences between ethnic groups were observed [50]. Typing for 22 lupus SNPs and adjusting each for their relative risk for lupus, Criswell and colleagues [51] found a similar relationship between age of lupus onset and total lupus genetic risk in Caucasians. Since young people have higher T-cell DNA methylation levels than older individuals, these studies suggest that young people with high DNA methylation levels may require more lupus genes to develop lupus but that those with a lesser genetic risk require a greater environmental impact on their T-cell epigenome. This also suggests that those with an even lower total genetic risk may only develop an ANA with age.

\section{Genetic/epigenetic interactions in women and men with lupus}

The strongest genetic factor predisposing patients to lupus is female sex. Women have two $\mathrm{X}$ chromosomes whereas men have just one, and the second $\mathrm{X}$ in women is inactivated by mechanisms that include DNA methylation. This raises the possibility that the second $\mathrm{X}$ chromosome may demethylate in women with active 
lupus, allowing overexpression of X-linked immune genes in women but not in men. CD40L (CD40LG) is an X-linked B-cell co-stimulatory molecule previously reported to be overexpressed on lupus lymphocytes, and murine lymphocytes overexpressing CD40L induce lupus $[52,53]$. Treating $\mathrm{CD}^{+} \mathrm{T}$ cells from healthy men and women with 5 -azaC caused CD40L overexpression on the female but not the male $\mathrm{T}$ cells, and bisulfite sequencing confirmed that women have one methylated and one unmethylated CD40LG gene and that 5-azaC demethylated the methylated gene. In contrast, men had only one, unmethylated gene, and 5-azaC had no further effect on CD40L gene methylation or expression [12].

Similar experiments compared CD40L on CD4 ${ }^{+} \mathrm{T}$ cells from men and women with active lupus. CD40L levels increased with disease activity on $\mathrm{CD}_{4}{ }^{+} \mathrm{T}$ cells from the women, and the degree of overexpression correlated with demethylation of their methylated CD40LG gene [12], similar to CD11a, CD70, perforin, and KIR [1,24]. In contrast, no change in CD40L expression levels was seen in men matched with the women for disease activity, consistent with their one unmethylated gene. Controls included demonstrating that the men had an increase in CD70 (encoded on chromosome 19) expression equivalent to that in women with active lupus [12]. These results indicate that genes on the female inactive $\mathrm{X}$ can demethylate and be overexpressed in women with lupus, potentially contributing to the female predisposition to this disease. This is supported by a report that men with Klinefelter's syndrome (XXY) develop lupus at approximately the same rate as women but that women with Turner's syndrome (XO) do not develop lupus [54].

Since the genetic and environmental contributions to lupus are variable and women are predisposed to lupus because their second $\mathrm{X}$ chromosome can demethylate, it is reasonable to propose that men with only one $\mathrm{X}$ chromosome might require a greater degree of T-cell DNA demethylation or a greater total genetic risk (or both) to develop a flare equal in severity to that of women. This was tested by comparing the interaction between the degree of DNA methylation in KIR and perforin genes, total genetic risk, and SLEDAI (Systemic Lupus Erythematosus Disease Activity Index) in men and women with lupus. Interestingly, the men had a slightly higher total genetic risk than the women $(P=0.05)$. Comparing the level of KIR or perforin methylation with SLEDAI scores showed no significant differences between the men and women. However, when the level of DNA methylation was adjusted by the total genetic risk and plotted against the SLEDAI (SLEDAI = risk/methylation) for each subject, the men required a stronger genetic/epigenetic interaction to achieve a flare equal in severity to that in women for both $\operatorname{KIR}(P=0.01)$ and perforin $(P=0.005)$ [55].

\section{Conclusions}

Epigenetic mechanisms, including DNA methylation, histone modifications, and miRNAs, play an essential role in regulating gene expression. Recent evidence indicates that dysregulation of these mechanisms alters gene expression in immune cells, contributing to the development of lupus in genetically predisposed people. Characterizing the epigenetic alterations and the mechanisms causing them is likely to provide important new insights into mechanisms causing human lupus and suggest new approaches to the treatment of this disease.

This article is part of the series on Epigenetics and rheumatic diseases, edited by Nan Shen. Other articles in this series can be found at http://arthritis-research.com/series/epigenetics

\section{Abbreviations}

5-azaC, 5-azacytidine; ANA, antinuclear antibody; dC, deoxycytosine; dnMEK, dominant negative MEK; Dnmt1, DNA methyltransferase 1; ERK, extracellular-signal-regulated kinase; HPK1, hematopoietic progenitor kinase 1; ICOS, inducible co-stimulatory molecule; IFNy, interferon-gamma; JNK, c-Jun N-terminal kinase; LFA-1, lymphocyte function-associated antigen 1; M $\varphi$, macrophage; $\mathrm{MHC}$, major histocompatibility complex; miRNA, microRNA; RANTES, regulated and normal T cell expressed and secreted; SAH, S-adenosylhomocysteine; SAM, S-adenosylmethionine; SLE, systemic lupus erythematosus; SLEDAl, Systemic Lupus Erythematosus Disease Activity Index; SNP, single-nucleotide polymorphism.

\section{Competing interests}

The authors declare that they have no competing interests.

\section{Acknowledgments}

The authors thank Julie Olivero for assistance in preparing the manuscript.

\section{Author details}

'Division of Rheumatology, Department of Internal Medicine, University of Michigan, 300 North Ingalls Building, Room 7C27, Ann Arbor, MI 48109-5422, USA. ${ }^{2}$ Section of Rheumatology, Ann Arbor VA Medical Center, 2215 Fuller Road, Ann Arbor, Ml 48105, USA.

Published: 29 January 2013

\section{References}

1. Richardson B: Primer: epigenetics of autoimmunity. Nat Clin Pract Rheumatol 2007, 3:521-527.

2. Li Y, Liu Y, Strickland FM, Richardson B: Age-dependent decreases in DNA methyltransferase levels and low transmethylation micronutrient levels synergize to promote overexpression of genes implicated in autoimmunity and acute coronary syndromes. Exp Geronto/ 2010, 45:312-322.

3. Gorelik GJ, Yarlagadda S, Richardson BC: Protein kinase Cdelta oxidation contributes to ERK inactivation in lupus T cells. Arthritis Rheum 2012, 64:2964-2974

4. Richardson B: Impact of aging on DNA methylation. Ageing Res Rev 2003, 2:245-261.

5. Fraga MF, Ballestar E, Paz MF, Ropero S, Setien F, Ballestar ML, Heine-Suñer D, Cigudosa JC, Urioste M, Benitez J, Boix-Chornet M, Sanchez-Aguilera A, Ling C, Carlsson E, Poulsen P, Vaag A, Stephan Z, Spector TD, Wu YZ, Plass C, Esteller $M$ : Epigenetic differences arise during the lifetime of monozygotic twins. Proc Natl Acad Sci U S A 2005, 102:10604-10609.

6. Kim HP, Leonard WJ: CREB/ATF-dependent T cell receptor-induced FoxP3 gene expression: a role for DNA methylation. J Exp Med 2007, 204:1543-1551.

7. Wilson CB, Rowell E, Sekimata M: Epigenetic control of T-helper-cell differentiation. Nat Rev Immunol 2009, 9:91-105.

8. Rozendaal L, Pals ST, Gleichmann E, Melief CJ: Persistence of allospecific 
helper T cells is required for maintaining autoantibody formation in lupuslike graft-versus-host disease. Clin Exp Immuno/ 1990, 82:527-532.

9. Quddus J, Johnson KJ, Gavalchin J, Amento EP, Chrisp CE, Yung RL, Richardson BC: Treating activated CD4+ T cells with either of two distinct DNA methyltransferase inhibitors, 5 -azacytidine or procainamide, is sufficient to cause a lupus-like disease in syngeneic mice. J Clin Invest 1993, 92:38-53.

10. Cornacchia E, Golbus J, Maybaum J, Strahler J, Hanash S, Richardson B: Hydralazine and procainamide inhibit T cell DNA methylation and induce autoreactivity. J Immunol 1988, 140:2197-2200.

11. Walport MJ: Lupus, DNase and defective disposal of cellular debris. Nat Genet 2000, 25:135-136

12. Lu Q, Wu A, Tesmer L, Ray D, Yousif N, Richardson B: Demethylation of CD40LG on the inactive $X$ in T cells from women with lupus. J Immunol 2007, 179:6352-6358.

13. Young HA: Regulation of interferon-gamma gene expression. J Interferon Cytokine Res 1996, 16:563-568.

14. Yung R, Williams R, Johnson K, Phillips C, Stoolman L, Chang S, Richardson B: Mechanisms of drug-induced lupus. III. Sex-specific differences in T cel homing may explain increased disease severity in female mice. Arthritis Rheum 1997, 40:1334-1343.

15. Richardson B, Scheinbart L, Strahler J, Gross L, Hanash S, Johnson M: Evidence for impaired T cell DNA methylation in systemic lupus erythematosus and rheumatoid arthritis. Arthritis Rheum 1990, 33:1665-1673

16. Golbus J, Palella TD, Richardson BC: Quantitative changes in T cell DNA methylation occur during differentiation and ageing. Eur I Immunol 1990, 20:1869-1872

17. Tan EM, Smolen JS, McDougal JS, Butcher BT, Conn D, Dawkins R, Fritzler MJ, Gordon T, Hardin JA, Kalden JR, Lahita RG, Maini RN, Rothfield NF, Smeenk R, Takasaki Y, van Venrooij WJ, Wiik A, Wilson M, Koziol JA: A critical evaluation of enzyme immunoassays for detection of antinuclear autoantibodies of defined specificities. I. Precision, sensitivity, and specificity. Arthritis Rheum 1999, 42:455-464

18. Sawalha AH, Jeffries M, Webb R, Lu Q, Gorelik G, Ray D, Osban J, Knowlton N, Johnson K, Richardson B: Defective T-cell ERK signaling induces interferonregulated gene expression and overexpression of methylation-sensitive genes similar to lupus patients. Genes Immun 2008, 9:368-378.

19. Strickland FM, Hewagama A, Lu Q, Wu A, Hinderer R, Webb R, Johnson K, Sawalha AH, Delaney C, Yung R, Richardson BC: Environmental exposure, estrogen and two $\mathrm{X}$ chromosomes are required for disease development in an epigenetic model of lupus. J Autoimmun 2012, 38:J135-143.

20. Gorelik G, Richardson B: Key role of ERK pathway signaling in lupus. Autoimmunity 2010, 43:17-22

21. Zandman-Goddard G, Solomon M, Rosman Z, Peeva E, Shoenfeld Y: Environment and lupus-related diseases. Lupus 2012, 21:241-250.

22. Chiurchiu V, Maccarrone M: Chronic inflammatory disorders and their redox control: from molecular mechanisms to therapeutic opportunities. Antioxid Redox Signal 2011, 15:2605-2641

23. Oates JC, Gilkeson GS: The biology of nitric oxide and other reactive intermediates in systemic lupus erythematosus. Clin Immunol 2006, 121:243-250.

24. Basu D, Liu Y, Wu A, Yarlagadda S, Gorelik GJ, Kaplan MJ, Hewagama A, Hinderer RC, Strickland FM, Richardson BC: Stimulatory and inhibitory killer Ig-like receptor molecules are expressed and functional on lupus $\mathrm{T}$ cells. J Immunol 2009, 183:3481-3487.

25. Liu Y, Kuick R, Hanash S, Richardson B: DNA methylation inhibition increases T cell KIR expression through effects on both promoter methylation and transcription factors. Clin Immunol 2009, 130:213-224.

26. Sunahori K, Juang YT, Kyttaris VC, Tsokos GC: Promoter hypomethylation results in increased expression of protein phosphatase $2 \mathrm{~A}$ in T cells from patients with systemic lupus erythematosus. J Immuno/ 2011, 186:4508-4517.

27. Jeffries MA, Dozmorov M, Tang Y, Merrill JT, Wren JD, Sawalha AH: Genomewide DNA methylation patterns in CD4+ T cells from patients with systemic lupus erythematosus. Epigenetics 2011, 6:593-601.

28. Kornberg RD, Lorch Y: Chromatin-modifying and -remodeling complexes. Curr Opin Genet Dev 1999, 9:148-151.

29. Lee DY, Hayes JJ, Pruss D, Wolffe AP: A positive role for histone acetylation in transcription factor access to nucleosomal DNA. Cell 1993, 72:73-84

30. Ura K, Kurumizaka H, Dimitrov S, Almouzni G, Wolffe AP: Histone acetylation: influence on transcription, nucleosome mobility and positioning, and linker histone-dependent transcriptional repression. EMBO J 1997, 16:2096-2107.

31. Barski A, Cuddapah S, Cui K, Roh TY, Schones DE, Wang Z, Wei G, Chepelev I, Zhao K: High-resolution profiling of histone methylations in the human genome. Cell 2007, 129:823-837.

32. Lachner M, O'Sullivan RJ, Jenuwein T: An epigenetic road map for histone lysine methylation. J Cell Sci 2003, 116 (Pt 11):2117-2124.

33. Murr R: Interplay between different epigenetic modifications and mechanisms. Adv Genet 2010, 70:101-141.

34. Hu N, Qiu X, Luo Y, Yuan J, Li Y, Lei W, Zhang G, Zhou Y, Su Y, Lu Q: Abnormal histone modification patterns in lupus CD4+T cells. J Rheumatol 2008, 35:804-810.

35. Zhao M, Wu X, Zhang Q, Luo S, Liang G, Su Y, Tan Y, Lu Q: RFX1 regulates CD70 and CD11a expression in lupus $T$ cells by recruiting the histone methyltransferase SUV39H1. Arthritis Res Ther 2010, 12:R227.

36. Zhao M, Sun Y, Gao F, Wu X, Tang J, Yin H, Luo Y, Richardson B, Lu Q: Epigenetics and SLE: RFX1 downregulation causes CD11a and CD70 overexpression by altering epigenetic modifications in lupus CD4+ T cells. J Autoimmun 2010, 35:58-69.

37. Zhou Y, Qiu X, Luo Y, Yuan J, Li Y, Zhong Q, Zhao M, Lu Q: Histone modifications and methyl-CpG-binding domain protein levels at the TNFSF7 (CD70) promoter in SLE CD4+T cells. Lupus 2011, 20:1365-1371.

38. Zhang Q, Long H, Liao J, Zhao M, Liang G, Wu X, Zhang P, Ding S, Luo S, Lu Q: Inhibited expression of hematopoietic progenitor kinase 1 associated with loss of jumonji domain containing 3 promoter binding contributes to autoimmunity in systemic lupus erythematosus. J Autoimmun 2011, 37:180-189.

39. Bartel DP: MicroRNAs: target recognition and regulatory functions. Cell 2009, 136:215-233.

40. Ding S, Liang Y, Zhao M, Liang G, Long H, Zhao S, Wang Y, Yin H, Zhang P, Zhang Q, Lu Q: Decreased microRNA-142-3p/5p expression causes CD4+ $T$ cell activation and $B$ cell hyperstimulation in systemic lupus erythematosus. Arthritis Rheum 2012, 64:2953-2963.

41. Yu D, Tan AH, Hu X, Athanasopoulos V, Simpson N, Silva DG, Hutloff A, Giles KM, Leedman PJ, Lam KP, Goodnow CC, Vinuesa CG: Roquin represses autoimmunity by limiting inducible T-cell co-stimulator messenger RNA. Nature 2007, 450:299-303.

42. Pan W, Zhu S, Yuan M, Cui H, Wang L, Luo X, Li J, Zhou H, Tang Y, Shen N: MicroRNA-21 and microRNA-148a contribute to DNA hypomethylation in lupus $C D 4+T$ cells by directly and indirectly targeting DNA methyltransferase 1. J Immunol 2010, 184:6773-6781.

43. Zhao S, Wang Y, Liang Y, Zhao M, Long H, Ding S, Yin H, Lu Q: MicroRNA-126 regulates DNA methylation in CD4+T cells and contributes to systemic lupus erythematosus by targeting DNA methyltransferase 1. Arthritis Rheum 2011, 63:1376-1386.

44. Stagakis E, Bertsias G, Verginis P, Nakou M, Hatziapostolou M, Kritikos H, lliopoulos D, Boumpas DT: Identification of novel microRNA signatures linked to human lupus disease activity and pathogenesis: miR-21 regulates aberrant $\mathrm{T}$ cell responses through regulation of PDCD4 expression. Ann Rheum Dis 2011, 70:1496-1506.

45. Fan W, Liang D, Tang Y, Qu B, Cui H, Luo X, Huang X, Chen S, Higgs BW, Jallal B, Yao $Y$, Harley JB, Shen N: Identification of microRNA-31 as a novel regulator contributing to impaired IL-2 production in T cells from patients with systemic lupus erythematosus. Arthritis Rheum 2012, 64:3715-3725.

46. Zhao X, Tang Y, Qu B, Cui H, Wang S, Wang L, Luo X, Huang X, Li J, Chen S, Shen N: MicroRNA-125a contributes to elevated inflammatory chemokine RANTES levels via targeting KLF13 in systemic lupus erythematosus. Arthritis Rheum 2010, 62:3425-3435.

47. Tang Y, Luo X, Cui H, Ni X, Yuan M, Guo Y, Huang X, Zhou H, de Vries N, Tak PP, Chen S, Shen N: MicroRNA-146A contributes to abnormal activation of the type I interferon pathway in human lupus by targeting the key signaling proteins. Arthritis Rheum 2009, 60:1065-1075.

48. Garchow BG, Bartulos Encinas O, Leung YT, Tsao PY, Eisenberg RA, Caricchio R, Obad S, Petri A, Kauppinen S, Kiriakidou M: Silencing of microRNA-21 in vivo ameliorates autoimmune splenomegaly in lupus mice. EMBO Mol Med 2011, 3:605-615.

49. Lessard CJ, Adrianto I, Ice JA, Wiley GB, Kelly JA, Glenn SB, Adler AJ, Li H, Rasmussen A, Williams AH, Ziegler J, Comeau ME, Marion M, Wakeland BE, Liang C, Ramos PS, Grundahl KM, Gallant CJ, Alarcón-Riquelme ME, Alarcón GS, Anaya JM, Bae SC, Boackle SA, Brown EE, Chang DM, Cho SK, Criswell LA, 
Edberg JC, Freedman BI, Gilkeson GS, et al: Identification of IRF8, TMEM39A, and IKZF3-ZPBP2 as susceptibility loci for systemic lupus erythematosus in a large-scale multiracial replication study. Am J Hum Genet 2012, 90:648-660.

50. Webb R, Kelly JA, Somers EC, Hughes T, Kaufman KM, Sanchez E, Nath SK, Bruner G, Alarcón-Riquelme ME, Gilkeson GS, Kamen DL, Richardson BC, Harley JB, Sawalha AH: Early disease onset is predicted by a higher genetic risk for lupus and is associated with a more severe phenotype in lupus patients. Ann Rheum Dis 2011, 70:151-156.

51. Taylor KE, Chung SA, Graham RR, Ortmann WA, Lee AT, Langefeld CD, Jacob CO, Kamboh MI, Alarcón-Riquelme ME, Tsao BP, Moser KL, Gaffney PM, Harley JB, Petri M, Manzi S, Gregersen PK, Behrens TW, Criswell LA: Risk alleles for systemic lupus erythematosus in a large case-control collection and associations with clinical subphenotypes. PLoS Genet 2011, 7:e1001311.

52. Crow MK, Kirou KA: Regulation of CD40 ligand expression in systemic lupus erythematosus. Curr Opin Rheumatol 2001, 13:361-369.

53. Higuchi T, Aiba Y, Nomura T, Matsuda J, Mochida K, Suzuki M, Kikutani H, Honjo T, Nishioka K, Tsubata T: Cutting edge: ectopic expression of CD40 ligand on B cells induces lupus-like autoimmune disease. J Immuno/ 2002, 168:9-12.

54. Scofield RH, Bruner GR, Namjou B, Kimberly RP, Ramsey-Goldman R, Petri M, Reveille JD, Alarcón GS, Vilá LM, Reid J, Harris B, Li S, Kelly JA, Harley JB:

Klinefelter's syndrome $(47, \mathrm{XXY})$ in male systemic lupus erythematosus patients: support for the notion of a gene-dose effect from the X chromosome. Arthritis Rheum 2008, 58:2511-2517.

55. Sawalha AH, Wang L, Nadig A, Somers EC, McCune WJ, Hughes T, Merrill JT, Scofield RH, Strickland FM, Richardson B: Sex-specific differences in the relationship between genetic susceptibility, T cell DNA demethylation and lupus flare severity. J Autoimmun 2012, 38:J216-222.

doi:10.1186/ar4125

Cite this article as: Patel DR, Richardson BC: Dissecting complex epigenetic alterations in human lupus. Arthritis Research \& Therapy 2013, 15:201. 